\title{
BMJ Open Quality Rapid implementation of virtual clinics due to COVID-19: report and early evaluation of a quality improvement initiative
}

\author{
Anthony William Gilbert (D) , ${ }^{1,2}$ Joe C T Billany, ${ }^{3}$ Ruth Adam, ${ }^{4}$ Luke Martin, ${ }^{3}$ \\ Rebecca Tobin, ${ }^{3}$ Shiv Bagdai, ${ }^{3}$ Noreen Galvin, ${ }^{4}$ lan Farr, ${ }^{4}$ Adam Allain, ${ }^{3}$ \\ Lucy Davies, ${ }^{3}$ John Bateson ${ }^{4}$
}

To cite: Gilbert AW, Billany JCT,

Adam $\mathrm{R}$, et al. Rapid implementation of virtual clinics due to COVID-19: report and early evaluation of a quality improvement initiative. BMJ Open Quality 2020;9:e000985. doi:10.1136/ bmjoq-2020-000985

Received 3 April 2020 Revised 8 May 2020 Accepted 13 May 2020
Check for updates

(C) Author(s) (or their employer(s)) 2020. Re-use permitted under CC BY. Published by BMJ.

${ }^{1}$ Therapies Department, Royal National Orthopaedic Hospital NHS Trust, Stanmore, UK

${ }^{2}$ School of Health Sciences, University of Southampton, Southampton, UK

${ }^{3}$ Operational Management, Royal National Orthopaedic Hospital NHS Trust, Stanmore, UK

${ }^{4}$ Improvement Team, Royal National Orthopaedic Hospital NHS Trust, Stanmore, UK

Correspondence to Anthony William Gilbert; anthony.gilbert@nhs.net

\section{ABSTRACT}

Background The COVID-19 outbreak has placed the National Health Service under significant strain. Social distancing measures were introduced in the UK in March 2020 and virtual consultations (via telephone or video call) were identified as a potential alternative to face-to-face consultations at this time.

Local problem The Royal National Orthopaedic Hospital (RNOH) sees on average 11200 face-to-face consultations a month. On average $7 \%$ of these are delivered virtually via telephone. In response to the COVID-19 crisis, the RNOH set a target of reducing face-to-face consultations to $20 \%$ of all outpatient attendances. This report outlines a quality improvement initiative to rapidly implement virtual consultations at the $\mathrm{RNOH}$.

Methods The COVID-19 Action Team, a multidisciplinary group of healthcare professionals, was assembled to support the implementation of virtual clinics. The Institute for Healthcare Improvement approach to quality improvement was followed using the Plan-Do-StudyAct (PDSA) cycle. A process of enablement, process redesign, delivery support and evaluation were carried out, underpinned by Improvement principles.

Results Following the target of $80 \%$ virtual consultations being set, $87 \%$ of consultations were delivered virtually during the first 6 weeks. Satisfaction scores were high for virtual consultations (90/100 for patients and 78/100 for clinicians); however, outside of the COVID-19 pandemic, video consultations would be preferred less than $50 \%$ of the time. Information to support the future redesign of outpatient services was collected.

Conclusions This report demonstrates that virtual consultations can be rapidly implemented in response to COVID-19 and that they are largely acceptable. Further initiatives are required to support clinically appropriate and acceptable virtual consultations beyond COVID-19.

Registration This project was submitted to the RNOH's Project Evaluation Panel and was classified as a service evaluation on 12 March 2020 (ref: SE20.09).

\section{INTRODUCTION}

The 2019 novel coronavirus (COVID 19) outbreak was first reported in Wuhan, China and reached the UK on 31 January 2020. On 11 March 2020, the WHO declared the
COVID-19 virus a pandemic. ${ }^{1}$ COVID-19 mainly affects the upper respiratory tract, and associated clinical symptoms can be mild, severe or critical. ${ }^{2}$ The COVID-19 virus spreads primarily through droplets of saliva or discharge from the nose when an infected person coughs or sneezes. Social distancing measures have been established, with the UK public being placed on 'lockdown' from 23 March $2020^{3}$ to avoid transmission of the disease.

Physical attendance at outpatient clinics puts patients at risk of spreading COVID-19. Virtual consultations (VCs) are an important way for patients to access their care without this risk. There has been a surge in the interest for VC in response to COVID-19, ${ }^{45}$ with the National Health Service (NHS) in the UK releasing new information governance guidance for their use. ${ }^{6}$

The Royal National Orthopaedic Hospital $(\mathrm{RNOH})$ is a specialist tertiary centre in Middlesex, UK. On average, 11200 monthly face-to-face (F2F) consultations are held across two outpatient sites at the RNOH across a range of pathways.

The RNOH was actively developing virtual clinics prior to COVID-19 in line with the NHS Long Term Plan $^{7}$ regarding reduction in F2F outpatient appointments. One of the project team had previously investigated the acceptability of $\mathrm{VC}^{89}$ and is actively researching this area. ${ }^{10}$ In November 2019, the operational management team agreed to use the VC platform Attend Anywhere with the licence for use granted on 27 February 2020. On 5 March 2020, in response to the growing COVID-19 crisis, a target of reducing F2F clinics to $20 \%$ of all outpatient attendances was set. The COVID-19 Action Team was established to support the delivery of this target. 
In June 2018, the RNOH committed to applying the Institute for Healthcare Improvement (IHI) approach to quality improvement (QI) to all applicable change processes and established an improvement team to support delivery of this strategy. The IHI method is a formal approach which includes a clear process for thinking through, conducting and analysing the change ideas in a Plan-Do-Study-Act (PDSA) cycle. ${ }^{11}$ Normally the improvement team trains and coaches front-line teams to lead and deliver changes, but COVID-19 needed a rapid response, so experienced and skilled members of the improvement team joined the COVID-19 Action Team to support an improvement approach at pace.

The aim of the project was for $80 \%$ of all $\mathrm{RNOH}$ outpatient appointments to be delivered as VC (using Attend Anywhere or telephone) within 11 days of the target being set (target $80 \%$ from 16 March 2020). The secondary aim was to collect data to support the design of a substantive legacy of VC post-COVID-19.

\section{METHODS}

\section{Early enablement}

The goal of $80 \%$ VC was set and communicated across all clinical staff. Clinical staff were asked to screen clinical lists and identify patients suitable for a VC (either a telephone consultation (TEL) or a video consultation (VID)) rather than F2F for the next 3 weeks. Software upgrades and hardware deployment began immediately and were completed within 24 hours across both sites at the RNOH.

\section{Process redesign and delivery support}

The COVID-19 Action Team was established to rapidly implement $\mathrm{VC}$ across the RNOH. The multidisciplinary team consisted of operational management and strategists, a project manager, QI personnel, a clinical research fellow and data management support. The team provided a variety of skills and resources to facilitate implementation. Daily meetings were scheduled to identify processes that needed to be redesigned to facilitate VC. Issues and actions logs were created to identify and overcome obstacles to implementation.

\section{Measures}

The overall approach to assess the impact of the intervention was straightforward: the percentage of patients undertaking VC (TEL or VID) compared with F2F. A combination of manual data collection of clinic lists and data taken from the $\mathrm{RNOH}$ patient management system was used to identify the proportion of patients undergoing VC. A simple, bespoke patient and clinician satisfaction questionnaire was developed to capture patient and clinician experience. This included the summative question 'how satisfied were you with the virtual clinic?' scored out of 100. These data collection methods were supplemented with informal observation and PDSA cycles.

\section{Analysis}

Descriptive statistics were used to analyse quantitative data. A thematic analysis of qualitative data was used to illustrate the underlying reasons behind the quantitative data.

\section{Project registration}

This project was submitted to the RNOH's Project Evaluation Panel and was classified as a service evaluation on 12 March 2020 (ref: SE20.09).

\section{RESULTS}

Between 5 and 27 March, a large number of PDSA cycles were undertaken simultaneously across the five main areas shown in table 1 to support rapid implementation of both telephone and video virtual clinics. Coordination of activity and management of interdependencies were managed via the daily implementation group teleconference. PDSAs were considered, and appropriate action to expand, redesign or retest was agreed.

Figure 1 and table 2 demonstrate the per cent change of the different consultation types to achieve the target $80 \% \mathrm{VC}$, with the majority of VCs conducted using TEL. figure 2 demonstrates the proportion of virtual outpatient activity.

\section{End of clinic reviews and patient feedback}

As outlined in table 1, a simple evaluation tool was developed to capture patient and clinician experience of virtual clinics from 16 March 2020. These results are demonstrated in table 3. Feedback was reviewed and discussed during daily COVID-19 Action Team meetings.

Patient satisfaction scores were high $(90 / 100)$ for both telephone and video consultations. However, patients were more likely to consider using phone consultations again after a phone appointment (94\% of patients) than video consultation patients wanting a further video appointment (36\% of patients).

Open-ended qualitative data provided an overview of some of the potential reasons for high satisfaction among patients. These included the following:

- The offer of an alternative to F2F during the COVID-19 pandemic.

- Reduced travel times.

- Reduced waiting times.

- Reduced impact of travel on symptoms.

Open-ended qualitative data also provided an overview of some of the potential reasons for high satisfaction amongst patients and clinicians. These included the following:

- VG worked particularly well when the patient was already known to the clinician.

- VID was useful to assess a range of movements or visually assess a patient (figure 3).

- VC ran quicker than traditional F2F clinics.

Common reasons for poor satisfaction for both patients and clinicians included the following:

- Variable sound and picture quality. 


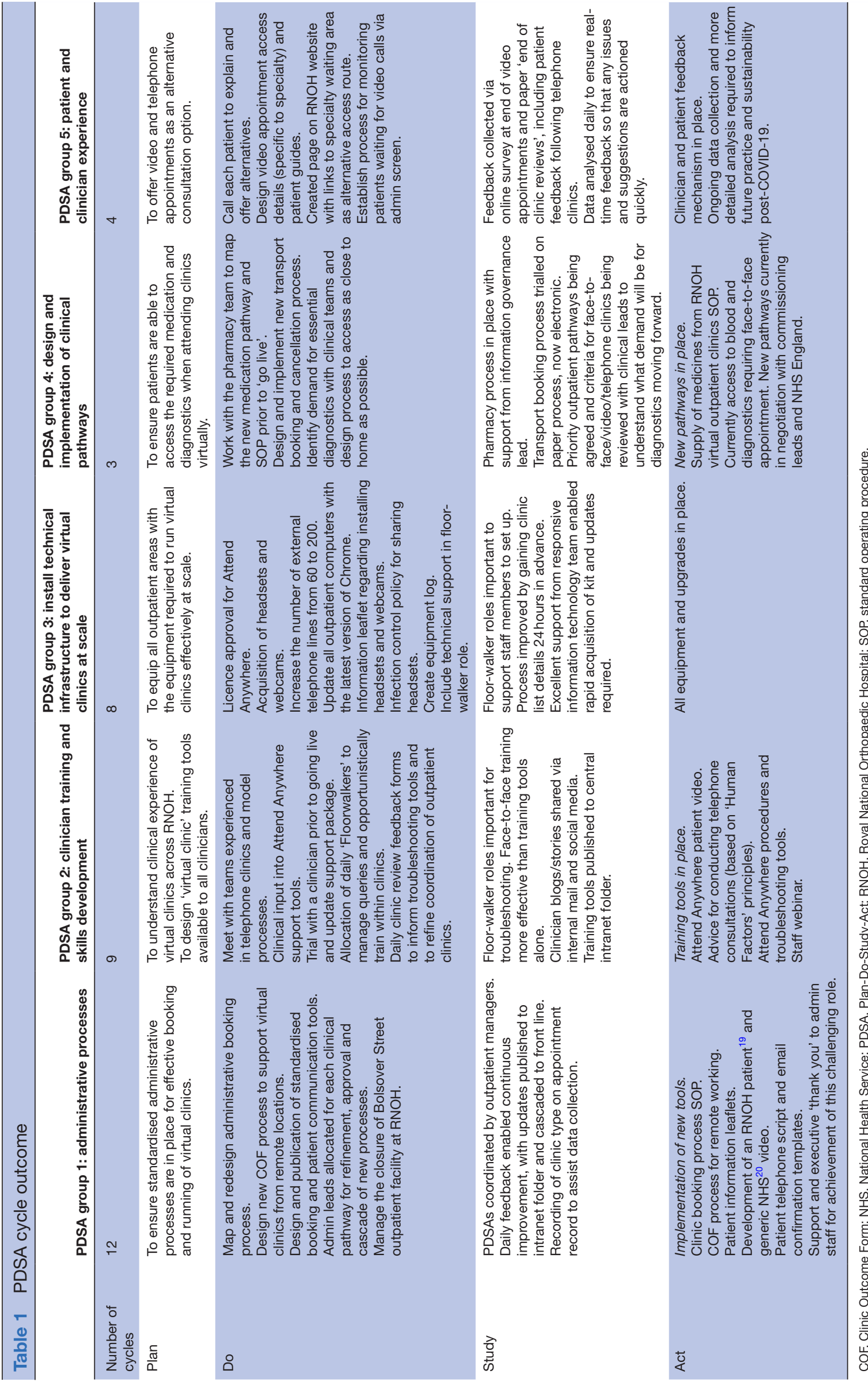




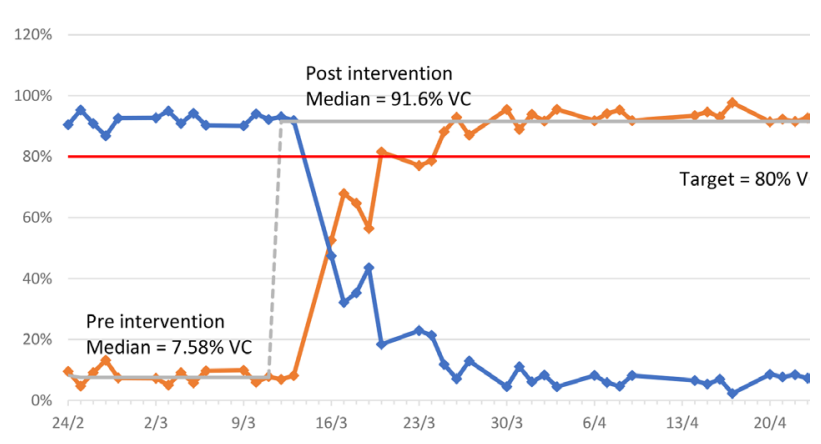

Figure 1 Run chart of virtual consultation (VC) and face-toface (F2F) outpatient clinics.

- Low confidence levels with using the technology; both patients and clinicians required support with setting up the hardware and software.

- Equipment issues with outdated software (eg, using Internet Explorer or not having up-to-date phone/ tablet/computer operating system software).

- Patients occasionally were left waiting in the virtual waiting area without having been acknowledged by the hospital.

These feedback forms were reviewed on a daily basis and informed the PDSA cycles.
Throughout the QI initiative, the COVID-19 Action Team collected information to support the future roll-out of VC after COVID-19. We now have in place all the technical elements to deliver outpatient appointments in a variety of ways appropriate to patient and clinician preference and convenience, and in the most effective way for the organisation. Prior to restarting a full outpatient service, a formal evaluation of patient and clinician experience will be undertaken. In addition, patient and staff stakeholder sessions will be held to inform any potential redesign of traditional outpatient models of care to incorporate VC.

\section{DISCUSSION}

The COVID-19 Action Team achieved the set goal of $80 \%$ VC by week 2. The use of QI methodology, specifically the use of repeated PDSA cycles, was essential to identify and overcome barriers to VC implementation.

The rapid implementation of $\mathrm{VC}$ was achieved due to the considerable resources directed to support it. The RNOH Senior Leadership Team clearly communicated $\mathrm{VC}$ as an important way to manage patients during the COVID-19 pandemic. The formation of the COVID-19 Action Team provided the initial resources to support patients and clinicians across the $\mathrm{RNOH}$ to engage with VC. The multidisciplinary nature of the COVID-19

\begin{tabular}{|c|c|c|c|c|c|c|c|c|c|}
\hline & $\begin{array}{l}\text { Baseline } \\
\text { week } 1 \\
\text { (w/c } 2 \text { March } \\
\text { 2020) }\end{array}$ & $\begin{array}{l}\text { Baseline week } \\
2(w / c 9 \text { March } \\
2020)\end{array}$ & & $\begin{array}{l}\text { VC week } 1 \\
\text { (w/c } 16 \text { March } \\
\text { 2020) }\end{array}$ & $\begin{array}{l}\text { VC week } 2 \\
\text { (w/c } 23 \text { March } \\
2020)\end{array}$ & $\begin{array}{l}\text { VC week } 3 \\
\text { (w/c } 30 \text { March } \\
\text { 2020) }\end{array}$ & $\begin{array}{l}\text { VC week } 4 \\
\text { (w/c } 6 \text { April } \\
\text { 2020) }\end{array}$ & $\begin{array}{l}\text { VC week } 5 \\
\text { (w/c } 13 \text { April } \\
\text { 2020) }\end{array}$ & $\begin{array}{l}\text { VC week } 6 \text { (w/c } \\
20 \text { April } 2020)\end{array}$ \\
\hline$\% \mathrm{~F} 2 \mathrm{~F}(\mathrm{n})$ & 92.73 (3634) & 92.27 (3535) & \multirow{2}{*}{$\begin{array}{l}\text { (target } \\
80 \% \\
\text { VC) }\end{array}$} & 37.31 (529) & $15.14(194)$ & $6.96(82)$ & $6.72(88)$ & $5.47(62)$ & $8.18(133)$ \\
\hline$\%$ VID (n) & - & - & & $3.80(54)$ & $6.71(86)$ & $8.40(99)$ & $6.26(82)$ & $6.00(68)$ & $8.18(133)$ \\
\hline
\end{tabular}

F2F, face-to-face; TEL, telephone consultation; VC, virtual consultation; VID, video consultation; w/c, week commencing.

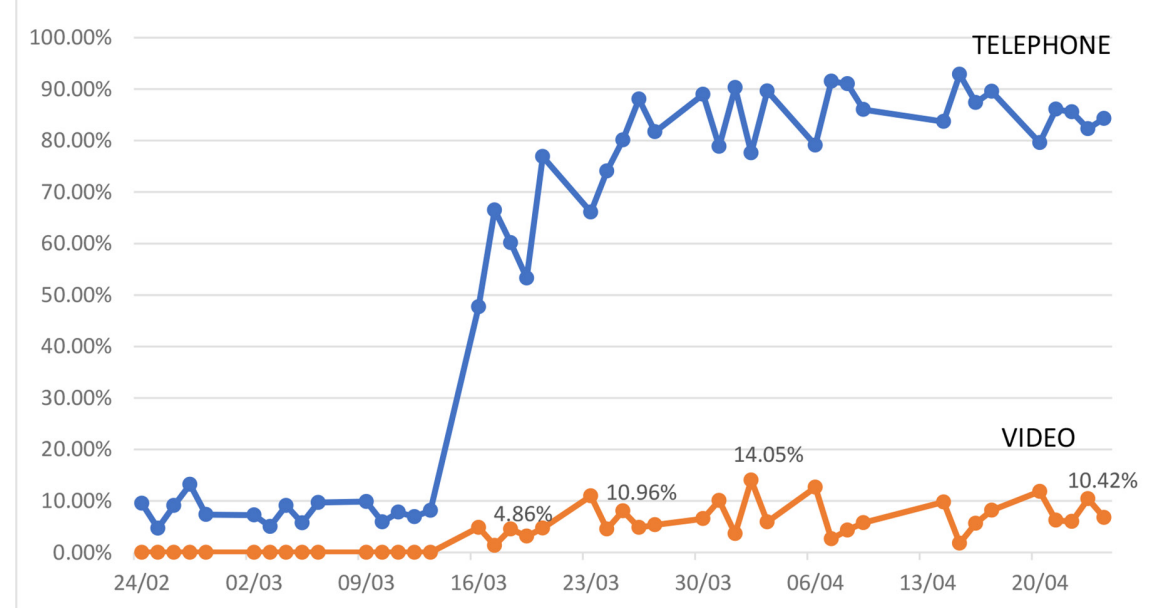

Figure 2 TEL and VID clinics - proportion of total virtual outpatient activity. 
Table 3 Summary of feedback from end of clinic reviews

\begin{tabular}{|c|c|c|c|c|c|}
\hline & & Responses (n) & Mean satisfaction score & Range & Virtual clinic again? \\
\hline \multirow[t]{2}{*}{ Patient feedback } & Phone & 111 & $90 / 100$ & $(30-100)$ & $94 \%$ yes \\
\hline & Video & 104 & $85 / 100$ & $(0-100)$ & $44 \%$ yes \\
\hline Clinician feedback & Video & 51 & $78 / 100$ & $(0-100)$ & $49 \%$ yes \\
\hline Virtual clinic total & & 242 & $87 / 100$ & $(0-100)$ & $73 \%$ \\
\hline
\end{tabular}

N/A, not available; VC, virtual consultation.

Action Team, with the ability to draft in extra personnel as required, ensured a wide range of skills and abilities to respond to the dynamic and complex circumstances of implementation. While this QI initiative was delivered in one Trust across two sites, the lessons learnt are relevant in other healthcare settings (table 4).

The NHS Long Term Plan clearly sets out digital requirements needed to support NHS services. ${ }^{7}$ VC features heavily on the RNOH Trust objectives, with VC due to be phased in. The catalyst for VC implementation was the COVID-19 pandemic. This unique situation required urgency to rapidly implement these changes; patients and staff were largely understanding of the necessity for VC and grateful for the swift response to the pandemic.

The $\mathrm{RNOH}$ is dedicated to supporting the use of $\mathrm{VC}$, in accordance with the NHS Long Term Plan. ${ }^{7}$ The key focus of the COVID-19 Action Team was to implement $\mathrm{VC}$ at pace. A secondary objective was to collect data to support the design of a substantive legacy of VC. Further stakeholder engagement initiatives and the use of frameworks ${ }^{12}$ or theories of implementation ${ }^{13}$ will support this. As we have found in this QI initiative, multidisciplinary working is key.

The majority of patients who underwent VC elected for a phone call (TEL) rather than a video call (VID). TELs have previously been found to be equally clinically effective as usual care,${ }^{14}$ although TELs were associated with lower patient satisfaction. A qualitative interview study with participants from the PhysioDirect telephone and advice service ${ }^{15}$ found that the telephone service was broadly acceptable, but it was described as impersonal' and many were sceptical about the ability of TELs

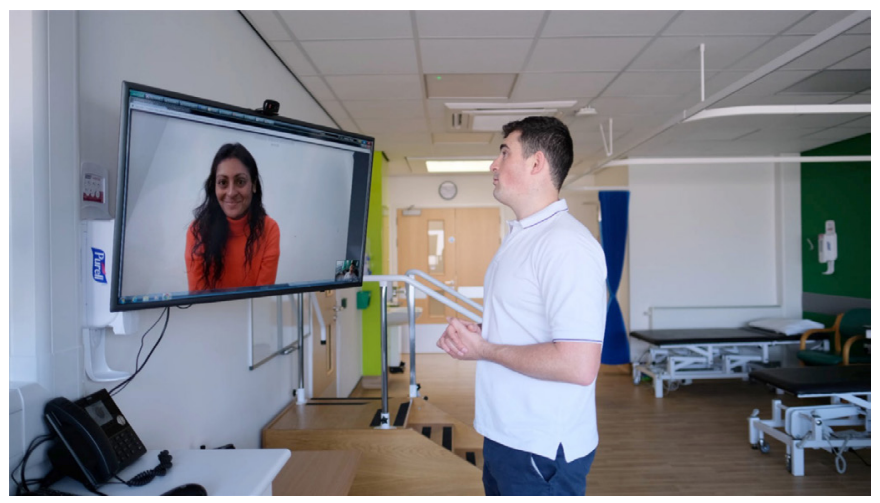

Figure 3 Video call between patient and clinician. to achieve the goal of the session. For many the PhysioDirect service provided a 'route in' to care. The satisfaction of phone calls in our project was high $(90 / 100)$, and approximately $94 \%$ indicated they would prefer a F2F call in the future. While TEL has proven to be a useful way to manage patients during the COVID-19 pandemic, further work needs to be done to understand its effectiveness and acceptability at the $\mathrm{RNOH}$ in the future.

Previous research ${ }^{9}$ at the $\mathrm{RNOH}$ investigating patient preferences for types of appointments found that approximately $50 \%$ of patients found the use of Skype to be acceptable for a follow-up consultation. These preferences were situational and fluid; patients stated they might choose VID or F2F under differing circumstances. The COVID-19 pandemic is a situation which has forced patients to undergo VC regardless of their preferences. Of those who underwent $\mathrm{VC}$ in our project, approximately half indicated they would prefer F2F for their next appointment. This is in keeping with a report ${ }^{16}$ that found that, from a survey of 2000 people, $55 \%$ would be willing to have a consultation for advice on an ongoing problem. Further research at the RNOH into preferences will likely sustain a legacy of clinically appropriate and acceptable VCs.

Greenhalgh et $a l^{17}$ found that videoconferencing consultations appeared to work better when the patient and clinician knew each other. It is not obvious from our early evaluation data whether or not this is the case in our project, however, informal feedback from some clinicians indicates that having a prior relationship with the patient may have enhanced the consultation. Technical challenges have previously been shown to be prohibitive, ${ }^{17}$ and those encountered in our project occasionally led to abandonment of VID. Clinicians often responded to these issues by abandoning the VID and transferring to TEL, or in cases where it was the sound that was mainly disrupted, they spoke over TEL while capturing images from VID to enable an assessment. Individual agency and reflexive monitoring played an important part in the successful implementation of VC. ${ }^{18}$

Significant resources were intensively deployed to deliver this rapid implementation of VC. They included three additional members of staff almost full time to support the roll-out, the cost of hardware, software, 


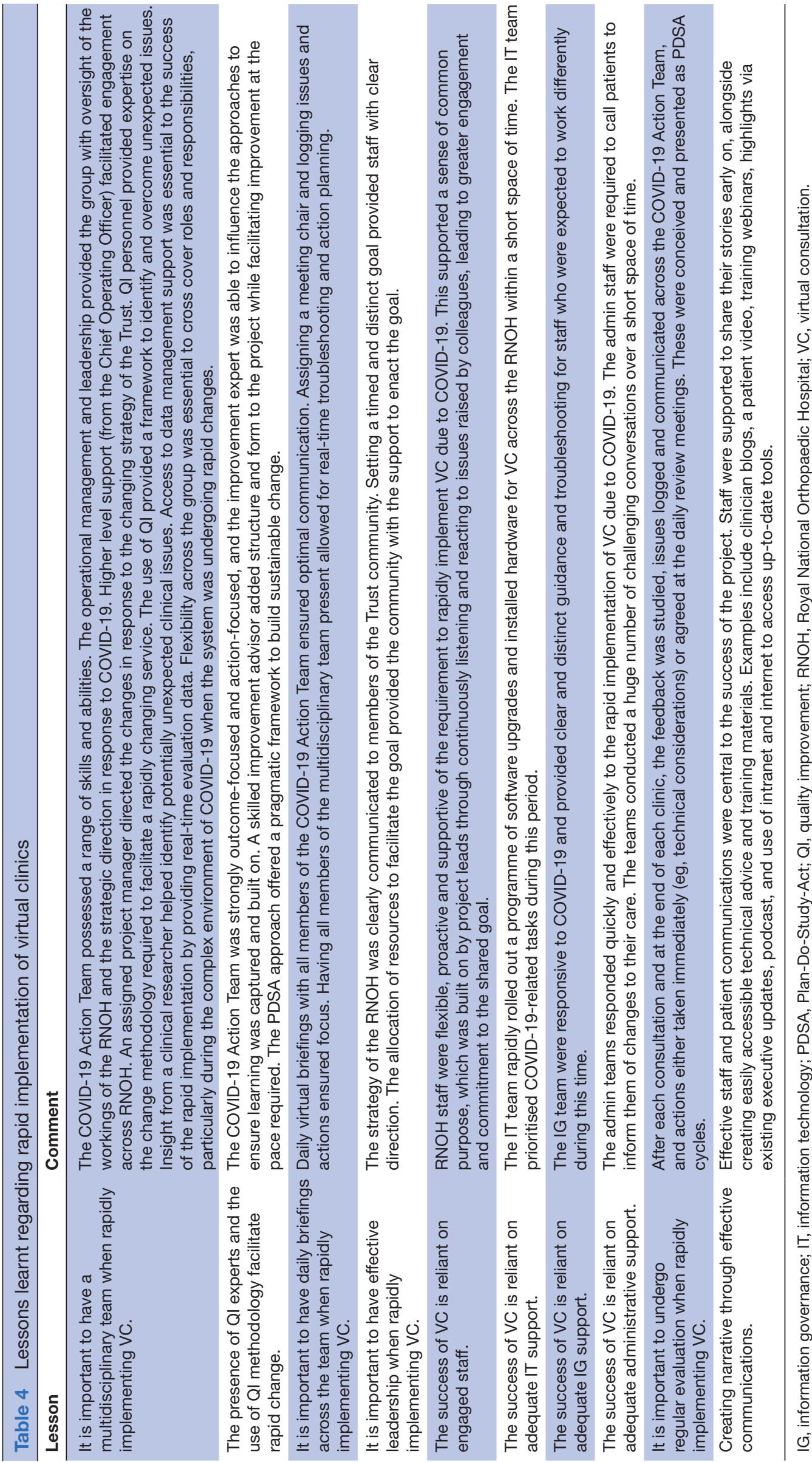


information technology and telephone infrastructure. These costs are rarely reported in the literature ${ }^{17}$ and will need to be taken into account when commissioning digitally supported services in the future. Virtual clinics offer potential savings to the NHS which need to be further scoped. Savings for patients included the reduction in time spent travelling and the cost of travelling.

$\mathrm{VC}$ is not a novel approach to delivering outpatient appointments in healthcare, but this paper discusses an extremely rapid adoption. To our knowledge, this is the first report of an NHS hospital evaluating rapid implementation of VCs due to COVID-19.

The findings must be interpreted in light of their limitations. This was not a research project but a rapid evaluation of VC implementation. The pace of change led to some missing data which were manually collected wherever possible. The pragmatic approach described here does not seek to test or demonstrate statistical significance. Future research studies evaluating the effectiveness and acceptability of $\mathrm{VC}$ are required, particularly as services return to a 'new normal' after COVID-19.

Commitment from clinicians and administrators was initially due to the unusual circumstances of COVID-19 and the imperative to stop all non-essential F2F work, but engagement was maintained by continuous multichannel communications throughout the project. The future goal is to maintain a clinically appropriate level of VC post-COVID-19; the improvement-driven approach described in this paper has led to wide engagement, a clear plan of action and objective data to support this aim.

The implementation was within an orthopaedics setting; however, the findings from this report have been reported in a way to be as general as possible to allow for transportability.

\section{CONCLUSION}

This QI initiative demonstrates that rapid implementation of virtual clinics can be achieved in response to the COVID-19 pandemic. The rapid implementation of VCs required a dedicated multidisciplinary team, expertise in operational management, QI, clinical care and data analysis. It required whole systems support from the RNOH Senior Leadership Team, information technology team, information governance team, administrative teams and clinical staff. This is a pragmatic QI initiative that was conducted at pace and must be considered in light of its limitations. To our knowledge this is the first report of rapid implementation of VCs across an NHS Hospital Trust conducted as a consequence of COVID-19. The findings from this report will be of interest to healthcare organisations looking to convert F2F clinics to virtual clinics. A structured and planned approach using QI methodology will be required to facilitate a return to F2F clinics as the COVID-19 situation allows.
Twitter Anthony William Gilbert @awgilbert11 and Joe C T Billany @JoeBillany

Acknowledgements The authors wish to acknowledge several people from the Royal National Orthopaedic Hospital: the information technology team for their support with the hardware and software, the information governance team for their expertise on data protection and privacy impact, the Research and Innovation Centre for prompt review and registration of the project, and the administration staff for contacting patients and clinicians who participated in the virtual clinics. Finally, the authors are grateful to Kelly Easton, whose contributions at the outset were essential to the delivery of this quality improvement initiative.

Contributors AWG, JCTB, RA, LM, RT, SB, AA and LD made substantial contributions to the design of the work. AWG, JCTB, RA, NG, IF and JB were involved in the collection, analysis and interpretation of data. AWG drafted the work with JCTB, RA, LM and JB. All authors critically revised the draft, gave final approval of the version to be published and are accountable for all aspects of the work. AWG is the guarantor of the manuscript.

Funding This quality improvement initiative was internally funded. AWG is funded by a National Institute for Health Research (NIHR) Clinical Doctoral Research Fellowship for this research project (ICA-CDRF-2017-03-025).

Disclaimer This paper presents independent research funded by the National Institute for Health Research (NIHR). The views expressed are those of the authors and not necessarily those of the NHS, the NIHR or the Department of Health and Social Care.

Competing interests None declared.

Patient and public involvement Patients and/or the public were not involved in the design, or conduct, or reporting, or dissemination plans of this research.All patients were given the opportunity to feedback their experience at the end of each consultation. This data was continuously evaluated and used to inform service development.

Patient consent for publication Not required.

Provenance and peer review Not commissioned; externally peer reviewed.

Open access This is an open access article distributed in accordance with the Creative Commons Attribution 4.0 Unported (CC BY 4.0) license, which permits others to copy, redistribute, remix, transform and build upon this work for any purpose, provided the original work is properly cited, a link to the licence is given, and indication of whether changes were made. See: https://creativecommons.org/ licenses/by/4.0/.

ORCID iD

Anthony William Gilbert http://orcid.org/0000-0003-2526-8057

\section{REFERENCES}

1 WHO. World health organisation Corobovirus disease 2019 (COVID-19) situation Report-51 2020. Available: https://www.who.int/ docs/default-source/coronaviruse/situation-reports/20200311-sitrep51-covid-19.pdf?sfvrsn=1ba62e57 10 [Accessed 29 Mar 2020].

2 He F, Deng Y, Li W. Coronavirus disease 2019 (COVID-19): what we know? J Med Virol 2020.

3 England PH. Number of coronovirus (COVID-19) cases and risk in the UK 2020. Available: https://www.gov.uk/guidance/coronavirus-covid19-information-for-the-public [Accessed 29 Mar 2020].

4 Greenhalgh T, Koh GCH, Car J. Covid-19: a remote assessment in primary care. BMJ 2020;368:m1182.

5 Greenhalgh T, Wherton J, Shaw S, et al. Video consultations for covid-19. BMJ 2020;368:m998.

6 NHSX. Covid-19 information governance advice for health and care professionals 2020, 2020. Available: https://www.nhsx.nhs.uk/ key-information-and-tools/information-governance-guidance/healthcare-professionals [Accessed 29 Mar 2020].

7 NHS. The NHS long term plan. Health Do, 2019.

8 Gilbert AW, Jaggi A, May CR. What is the patient acceptability of real time 1:1 videoconferencing in an orthopaedics setting? A systematic review. Physiotherapy 2018;104:178-86.

9 Gilbert AW, Jaggi A, May CR. What is the acceptability of real time 1:1 videoconferencing between clinicians and patients for a followup consultation for multi-directional shoulder instability? Shoulder Elbow 2019;11:53-9.

10 Gilbert AW, Jones J, Stokes M, et al. Protocol for the connect project: a mixed methods study investigating patient preferences 
for communication technology use in orthopaedic rehabilitation consultations. BMJ Open 2019;9:e035210.

11 Langley GL, Moen R, Nolan KM, et al. The improvement guide: a practical approach to enhancing organizational performance. 2nd edn. San Francisco: Jossey-Bass Publishers, 2009.

12 Greenhalgh T, Wherton J, Papoutsi C, et al. Beyond adoption: a new framework for theorizing and evaluating nonadoption, abandonment, and challenges to the scale-up, spread, and sustainability of health and care technologies. J Med Internet Res 2017;19:e367.

13 May CR, Johnson M, Finch T. Implementation, context and complexity. Implement Sci 2016;11:141.

14 Salisbury C, Montgomery AA, Hollinghurst S, et al. Effectiveness of PhysioDirect telephone assessment and advice services for patients with musculoskeletal problems: pragmatic randomised controlled trial. BMJ 2013;346:f43.

15 Pearson J, Richardson J, Calnan M, et al. The acceptability to patients of PhysioDirect telephone assessment and advice services; a qualitative interview study. BMC Health Serv Res 2016;16:104-04.

16 Castle-Clarke S. What will new technology mean for the NHS and its patients? four big technological trends, 2018. Available: https:// www.nuffieldtrust.org.uk/files/2018-06/1530028974_the-nhs-at-70 what-will-new-technology-mean-for-the-nhs-and-its-patients.pdf

17 Greenhalgh T, Shaw S, Wherton J, et al. Real-World implementation of video outpatient consultations at macro, meso, and micro levels: Mixed-method study. J Med Internet Res 2018;20:e150.

18 May C, Finch T, Implementing FT. Implementing, embedding, and integrating practices: an outline of normalization process theory. Sociology 2009;43:535-54.

19 Letocha J. RNOH virtual outpatient clinics: a patient guide (Royal national orthopaedic Hospital version), 2020. Available: https://youtu. be/1aL-WFe82xo [Accessed 31 Mar 2020].

20 Letocha J. Nhs virtual outpatient clinics: a patient guide (NHS version), 2020. Available: https://youtu.be/M39BPLy9vFE [Accessed 31 March 2020]. 